\title{
Team Teaching an Interdisciplinary First-Year Seminar on Magic, Religion, and the Origins of Science: A 'Pieces-to-Picture' Approach
}

\begin{abstract}
Melati Nungsari ${ }^{1}$, Maia Dedrick ${ }^{2}$, and Shaily Patel ${ }^{3}$
Abstract: Interdisciplinary teaching has been advocated as a means to foster cooperation between traditionally separate fields and broaden students' perspectives in the classroom. We explored the pedagogical difficulties of interdisciplinary team teaching through a first-year seminar in magic, religion, and the origins of science. Although many accounts in the literature suggest a more cohesive approach to interdisciplinary teaching, we first introduced the separate fields, their methodologies, and limitations before combining the insights from all three fields to analyze case studies relating to the main themes of the course. In this case study, we reflect on how this 'pieces-to-picture' method reduced student confusion when confronted with several disciplines in our classroom.
\end{abstract}

Keywords: Interdisciplinary Teaching, Team Teaching, Pedagogy, Graduate Student Teaching

Interdisciplinary teaching has been hailed as a first step in bridging the gap between increasingly separate fields in academia. Although many have spoken to the merits of interdisciplinary teaching as a means to broaden students' perspectives in the classroom, others have documented the difficulties faced by instructors who attempt to create connections between distinct theoretical lenses (Barisonzi \& Thorn, 2003; Borrego \& Newsmander, 2008; Shapiro \& Dempsey, 2010; Eisen \& Huang, 2014). In an article from the Chronicle of Higher Education, Lennard J. Davis argues that interdisciplinary teaching may even be dangerous, since "some kinds of knowledge may negate others” (Davis, 2007). For example, experimental psychological findings that humans often act impulsively when making decisions are contrary to the standard portrayal of humans in economics as being rational, calculating beings. Students also often enter the classroom with an inaccurate prior perception of the fields incorporated into the course (Beck-Winchatz \& Parra, 2013). In their article assessing non-science majors' views regarding the nature of science, BeckWinchatz and Parra found that students take scientific knowledge as absolute truth instead of acknowledging that it is inherently uncertain and constantly changing.

The purpose of this paper is to provide an overview of an interdisciplinary team-taught course on magic, religion, and science, the difficulties faced when executing the course, and the teaching method that we found most useful in dealing with the difficulties encountered. In particular, we stress the importance of introducing separate methodological sections covering each of the fields combined in the interdisciplinary course to reduce confusion on the students' part. This method of teaching, which takes on a multidisciplinary or 'pieces-to-picture' approach, is

\footnotetext{
${ }^{1}$ Department of Economics, Business Law, and Finance, Lacy School of Business, Butler University, 4600 Sunset Avenue, Indianapolis, IN 46208; mnungsar@butler.edu.

2 Department of Anthropology, The University of North Carolina - Chapel Hill, 301 Alumni Building, CB\#3115, Chapel Hill, NC 27599; mdedrick@live.unc.edu.

${ }^{3}$ Department of Religious Studies, The University of North Carolina - Chapel Hill, 125 Carolina Hall, CB\#3225, Chapel Hill, NC 27599; shailyp@email.unc.edu.
} 
different than the approach that has mostly been recommended in the interdisciplinary teaching literature, where previous authors have advocated presenting the course as an entirely new interdisciplinary field which contains elements from each of the distinct theoretical lenses used (Krometis, Clark, Gonzalez, \& Leslie, 2011). In our interdisciplinary seminar, introducing the separate fields and viewpoints with the associated shortcomings and advantages (i.e. the pieces) allowed students to better negotiate between different disciplines to comprehend the major themes of the course (i.e. the picture).

\section{Course Description}

All first-year students at the University of North Carolina at Chapel Hill (UNC) enroll in discussion-based seminars. These classes are usually small (up to 25 students), offered throughout the year, and cover a multitude of topics. As described on the official UNC first-year seminar website, these classes are intended to "offer an introduction to the intellectual life of the university and focus on how scholars pose problems, discover truths, resolve controversies, and evaluate knowledge.” (First Year Seminars Programs, n.d.)

Through an initiative of the Royster Society of Fellows at UNC, a select number of graduate students have the opportunity to independently design a team-taught interdisciplinary course. This program has been in place at UNC since 2006, with the first courses offered in Fall 2008. Due to the unique combination of fields involved in planning and executing the course and the amount of resources it takes to fund three individuals to teach one small course, these courses are either only taught once, or serve as a foundation for future interdisciplinary seminars that may be taught by the instructors. Previous Royster Fellows have also documented their experience teaching this distinctive seminar (Krometis et al., 2011).

Our course was titled "Magic, Religion and the Origins of Science" and was taught in Fall 2013. We spent two years developing the curriculum for this course. Our teaching team consisted of instructors from anthropology, economics, and religious studies. We set out to explore how various definitions of magic, religion, and science are constructed, maintained, and broken down throughout history. In achieving this goal, we hoped that students would learn to construct convincing analytical arguments; negotiate distinctions between magic, religion, and science in history; and develop an awareness of the various factors that determine the classifications made by analysts of these phenomena. Some of the questions asked in this seminar include the following:

- What is magic? How does it differ from religious practice?

- How could economic factors have influenced the Salem and European witch trials?

- Why have some types of healing been designated as scientific "medicine” while others are "shamanistic"?

- How have capitalism and colonialism affected the way in which certain societies around the world define and construct the notion of magic?

In this paper, we will focus on the main difficulty that we identified in the planning process. This difficulty can be summed up into one question: How can we incorporate all of the fields holistically into a seminar without confusing or overwhelming the students? In particular, even though the line between sociology (represented by our religious studies scholar) and anthropology is arguably blurry, incorporating an economic perspective into the curriculum as well was rather challenging. The 'pieces-to-picture' approach appeared to work in our context to solve this problem and helped

Journal of the Scholarship of Teaching and Learning, Vol. 17, No. 1, February 2017.

josotl.indiana.edu 
improve students' learning outcomes. Since this problem also appears in the broader context of interdisciplinary teaching, we will devote some time in the next section on exploring the meaning of doing interdisciplinary work and situate our seminar within the category of interdisciplinary classes.

\section{Defining Interdisciplinarity and Its Limits}

One of the reasons that interdisciplinary studies carry so little intellectual cachet is definitional ambiguity. Newell and Green claim that, "the term 'interdisciplinary studies' itself is so loosely and so inconsistently used that almost any course which does not fit neatly within disciplinary departments is apt to be labeled 'interdisciplinary”” (Newell \& Green, 1982). Indeed, the very mention of 'interdisciplinary' work calls to mind a jumble of related or partially related studies that produce dilettantism at best and misinformation at worst. There are avenues of inquiry, however, that lend themselves to interdisciplinary approaches for the simple fact that any singular disciplinary approach would yield but a facet of the whole-inquiries surrounding magic, for example. What is magic? How is it distinguished from religion and from science? Such questions can be answered using the methodologies inherent to one discipline, but they are best approached from a number of paradigms, each with particular benefits and limitations.

As previously mentioned, in our preparation to teach the seminar, we found it useful to explore the meaning of doing interdisciplinary work. Following the classification in the previously mentioned article by Newell and Green, interdisciplinary work can be delineated as follows. Firstly, interdisciplinary work consists of two or more distinct disciplines brought to bear upon a single subject matter. Therefore, studying magic from sociological, economic, and anthropological frameworks fits the first criterion.

Secondly, interdisciplinary work encourages a synthesis of the various approaches involved; it produces a coherent, integrated body of knowledge. Even though our course began as a multidisciplinary endeavor - that is, three separate disciplines remaining unintegrated-it evolved into a more coherent approach. To provide students with some preliminary footing in all three disciplines, it was necessary to introduce them to fundamental methodologies. Afterwards, all three methodologies were applied to various case studies, each related to the course's broader theme of magic, science, and religion. To better understand a case study like alchemy, for example, students learned about the economic history of gold, the "trappings" of alchemical processes, and the religious/philosophical underpinnings of turning base metal into gold or creating the Philosopher's Stone. The case studies, then, represent the interdisciplinary fruits (i.e. the picture) of earlier multidisciplinary efforts (i.e. the pieces).

Thirdly, interdisciplinary work must yield more knowledge than that produced by any constituent discipline. For example, the tension between economics and sociology (i.e. the tension between individual choice and social determinism) adds a richer resonance to the study of the individual within a larger social matrix. Why does an ailing woman seek to better her health through a Candomblé priestess instead of the Christian God? An economic approach to analyzing the issue might take into account factors that contribute to the woman's choice-immediate versus long-term results, financial versus non-financial cost, ease of accessibility. A sociological approach, on the other hand, might highlight the ways in which the "duties" of a Candomblé priestess are constructed vis-à-vis her counterpart in the Christian church or explain why the healing practices of such a priestess lie outside the scope of institutionalized religion. In order to

Journal of the Scholarship of Teaching and Learning, Vol. 17, No. 1, February 2017. josotl.indiana.edu 
understand more than one facet of our ailing patient, we must look to more than one disciplinary framework. To choose either economics or sociology would diminish the richness of our analysis.

This being said, there are major limitations to interdisciplinary approaches. One is that interdisciplinary work, by its very definition, touches only the surface of any given discipline. Previous scholars have also documented this consequence, emphasizing the tradeoff between breadth and depth of mastery of knowledge in interdisciplinary classes (Caviglia \& Hatley, 2004). For example, in our sociological methodology section, we focused primarily on the sociological explanations for the development of religion and the construction of magic as its "noninstitutionalized" other. That is, our discussion of the sociological approach was constructed along the social institution versus individual/non-institution binary. More refined methods of sociological analysis were not pursued at any length.

Finally, we found in the development and the execution of our course that a commitment to interdisciplinarity provides consistent challenges. Achieving the intellectual integration and coherence that interdisciplinarity demands is difficult, as a balance on the scale of interdependence between the instructors and their fields must be attained (Shapiro \& Dempsey, 2008). Given our decision to begin the course with distinct methodological units, our approach seemed, at first, more multidisciplinary than interdisciplinary. This collection of distinct methodologies, however, were better integrated as the semester continued, with each new case study serving as another opportunity to synthesize not only previously-learned methodologies, but also the results of the application and critiques of said methodologies.

\section{Classroom Description and Learning Goals}

We had 14 students in our classroom, all of whom were first-year undergraduates. Since the course was held in the fall, it was also one of their first college classes. The students participating in the seminar were overwhelmingly female, with only one male participant. Students came from a variety of interests - some already their prospective majors, but most did not. Although UNC generally attracts more students from North Carolina than not, students in our classroom were almost equally split into North Carolina residents and non-residents. We also found that our students were, on average, well prepared for college. Since our course was one of the first that they would take in college, we felt that it should serve as an introduction to learning and mastering skills that will benefit them in their college career and beyond. We designed the learning goals and assessments for the seminar to help achieve this.

Aside from forming an appreciation for the study of magic, religion and science, we chose to foreground certain broader goals that could be achieved through a treatment of the topics covered in course. Other scholars have also pointed to these goals as worthy of interdisciplinary endeavors (Caviglia \& Hatley, 2004; Weinberg \& Harding, 2004; Shapiro \& Dempsey, 2008). The first and perhaps most important was to introduce the idea of paradigms and personal epistemologies. In particular, we wanted students to realize that every individual is built as a sum of their life experiences, and that each of us has unique experiences that may influence how we interpret the workings of the world. This is especially important in a discussion-based course, where students come from a diverse array of backgrounds and must learn to respect each other in an academic setting. In addition, the notion of paradigms allowed students to examine assumptions and boundaries of the various disciplines that we studied and then determine the extent to which methodologies succeed or failed at addressing various aspects of life.

Journal of the Scholarship of Teaching and Learning, Vol. 17, No. 1, February 2017. josotl.indiana.edu 
The second goal of the course was to teach students to read and write critically. To read an article, pick up on its main points, and analyze and communicate one's thoughts clearly and precisely is a learned skill. In our experience as educators, students often claim that they have read articles assigned in the classroom, but when asked, fail to communicate the key points made by the author(s). We wanted students to grow accustomed to the tenor of academic writing in hopes to improve reading comprehension.

The third goal of the course was to ensure that students improved their oral skills. It was important to get the students to communicate ideas in a cogent and eloquent way, and to learn how to do so early in their college career. Along with the first learning goal, we felt it was important for the students to learn how to demonstrate respect for other opinions that may arise in the classroom, especially since we dealt with quite a number of topics that may strike students as being 'personal' or 'controversial', such as religion.

\section{Course Structure}

The course met twice weekly for 75 minutes each class period. For each class we assigned required readings, usually totaling no more than 30 pages per session. We collected reading journals every other week, which together made up $25 \%$ of student grades. On the same days we collected journals, we held quizzes in class, which contributed $15 \%$ of the grade. The final project included preparatory research encapsulated in an annotated bibliography, which included at least ten sources and made up another $25 \%$ of the final grade. The bibliography focused on a topic for debate at the end of the seminar. Debates were held on the last two class days and made up $25 \%$ of the final grade. The final $10 \%$ of the course grade depended on active class participation, including a class discussion lead.

In terms of the thematic direction of the course, we began by presenting students with definitions of religion, magic, and science, as provided by famed sociologist Rodney Stark. This was an excellent reading to start with because it provides strictly delineated definitions that the students or teachers were able to question or modify throughout the semester. Next, we introduced students to the methodologies of our fields: economics, sociology (represented by our religious studies scholar), and anthropology, spending one week on each field, with an extra session for economics. These sessions were crucial in order for students to understand and move beyond the boundaries between our fields, but it was not their favorite part of the course. The readings were dense and introduced students to perspectives on the world that were mostly new and unfamiliar to college first-years. Each graduate student taught the sessions on the field of her expertise.

After introducing students to tools of the three disciplines, we began case studies that were arranged chronologically. We started with alchemy, which is one of many phenomena that consist of an unexpected blend of magic, religion, and science. Although one of our main goals was for students to understand that magic is very much present in the world today, we also wanted them to learn the history of magic and science and how they came to be understood as separate fields of inquiry. Every single student knew the scientific method, but no students knew about science's origins. Our first reading on the subject addressed alchemy and its relationship to the economy in $17^{\text {th }}$-century England. Additional readings introduced the philosophy of alchemy, situated it historically, and explained its role in early America including its relationship to witchcraft and religion in Connecticut. In this way we made sure to address the issue in terms of its economic, religious, and magical components, as we did for all case studies. Additional case studies or areas of focus included witch trials, magic and the colonial encounter, the impacts of colonialism, black

Journal of the Scholarship of Teaching and Learning, Vol. 17, No. 1, February 2017.

josotl.indiana.edu 
versus white magic, healing magic and medicine, and magic and modernity. Students enjoyed the content of case studies throughout the course, and found them to be more engaging than our methods section.

\section{Assessments and Classroom Activities}

The assessments in our seminar were almost equally divided into the two categories of formative (reading journals, quizzes, and class-led discussions) and summative (annotated bibliography and final debates) assessments. To address our second learning goal of teaching students to read and write critically, we incorporated daily reading journals collected every two weeks. Students were asked to read one article assigned for each day with particular attention, synthesizing the material and writing a response to the article. This encouraged the students to think and reflect on what they read. However, there was a significant gap in what we expected the students to handle in terms of workload and what they could actually accomplish. We had initially required them to write a journal on each of the articles that were assigned; this proved to be too much, as we found that students were handing in subpar work, doing just enough to complete the assignment. About onethird of the way through the course, we adjusted the expectations and only required that they turn in one journal entry per day.

The journals provided a space in which students could continue to reflect back on how the readings we read connected to larger course themes. They also gave us opportunities to provide students with feedback on the depth of their engagement with the material on a regular basis. After receiving each assignment, we divided the journals among the teaching team in order to provide thorough feedback on writing style, content, and analysis. Throughout this process, we found that students attained more appropriate tones in their writing, included more specifics from the materials assigned, and demonstrated their increasing ability to contextualize the works more broadly.

We used the quizzes that were given every other week to assess students in two ways, the first being whether they had read the material assigned and the second being whether they had paid attention in the previous weeks' lectures. The quizzes consisted of 2-3 short answer questions, with one question being devoted to explaining a concept, term, or phenomenon that was not in the readings but was introduced during a previous lecture. Some examples of quiz questions are:

- In the first chapter of Marketplace of the Gods, Witham states the following: "In the aftermath of war, before the Japanese nation could rebuild itself from the ashes, its citizens began to experience a remarkable religious event. Through the late 1940s, they witnessed 'kamigami no rasshu awa', "rush hour of the gods" - a time when two thousand new religious groups sprang up, as if from nowhere.” Witham provides many explanations for this phenomenon. List two of them.

- List and define (briefly) Max Weber's two types of charisma.

- Summarize briefly (in no more than 2-3 sentences) one of the two sections you read from the 'Malleus Maleficarum'.

At the beginning of the seminar, we led discussion on the readings for the course and connected them to larger course themes and historical backgrounds. Next, each student chose a class during which to lead discussion, either independently or with one other student. We led any class discussion not covered by students for the remainder of the semester. At mid-term evaluations, students were highly enthusiastic about student-led discussions. By the end of the semester,

Journal of the Scholarship of Teaching and Learning, Vol. 17, No. 1, February 2017.

josotl.indiana.edu 
however, they had tired of hearing from other students and wished we had lectured and led discussions for a greater proportion of the sessions. With hindsight, an appropriate compromise would have been to ensure three students teamed up for each discussion session. With three people teams, we could have been more specific and demanding in our expectations of discussion leadership. Furthermore, there also would have been fewer sessions led by students and thus we would conclude student-led discussions as the novelty wore off for the rest of the course. We believe students would have been happiest had we reserved the last several sessions for teacherled lectures and discussions. Our experience of the success of student-led sessions agreed with that described by research in the literature regarding student-led seminars (Casteel \& Bridges, 2007). The difference is that the authors mentioned previously studied upper-level courses, and we found that even first-year students, with a bit of urging and guidance, could show success in this domain. The student-led discussions were, in our opinion, a great opportunity for students to enhance their public speaking skills, since they essentially put the students in charge of an entire class.

The final project and most heavily weighted assessment was a debate and preparation of an annotated bibliography documenting the resources to be used during the debate. For the final project, students were divided into teams of four and were randomly assigned to opposing sides for the two following statements: "Magic cannot inspire morality" and "Traditional healers are not doctors". We encouraged students to meet outside the classroom in order to plan their debate and prepare rebuttals in anticipation of their opponent's arguments. Attendance was mandatory for the two days when debates were held. After witnessing the debates, team members were asked to step outside while the remaining students in the classroom voted for which side presented the most convincing facts to support their arguments. This provided a way for students who were not debating to also participate in the classroom. Although we did assess how the participants worked as a team, we did not directly grade students on whether or not their team won; rather, we assigned individual grades to each participant on the team.

In preparation for the final project, we conducted informal debates in class. For example, for our first debate, which took place amidst our readings on alchemy, we divided the class into three teams, arguing three different positions: alchemy is magic, alchemy is religion, or alchemy is science. All students engaged in this activity and contributed to their team's arguments. In another interactive session, students devised their own religions in groups, and then we analyzed what made the inventions religions as opposed to some other phenomenon.

Students also enjoyed interactive activities, including videos, debates, and a guest speaker. For example, during the very first introductory class, we showed an Al-Jazeera documentary about witch trials in the Democratic Republic of the Congo. This documentary introduced the topic of the course in a way that demonstrated to students that the issue of magic and its interaction with science is pertinent in today's world. Magical beliefs held today are addressed using law and science and have consequences in terms of health disparities and discrimination. We challenged students on this first day of class to critique what they had seen, i.e. that the video depicts magical beliefs in a poor light. Is there anything positive about the local beliefs and laws or in this case were they all harmful and nonsensical? Although the students did not yet have the tools to unpack this case study, throughout the semester we continued to reflect back on this experience in order to understand the dynamic and morally complicated implications of magic as a modern phenomenon not located in the past.

Students also engaged with the material through discussions with guest speaker Professor Silvia Tomášková from the Department of Women’s and Gender Studies and Anthropology at UNC. We read chapters from her book on shamanism, entitled Wayward Shamans, which she then

Journal of the Scholarship of Teaching and Learning, Vol. 17, No. 1, February 2017. josotl.indiana.edu 
came to the class to discuss. It was useful to have an outside voice that continued to challenge students in order to modify their pre-conceived notions of the distinctions between magic, religion, and science. Tomášková was skilled at showing how categories, and in this case the definition of the shaman, have changed through time based on contemporaneous politics and agendas. Oftentimes our view of the past and even the present tells us more about ourselves than the phenomena of study. In particular, we read chapters from her book that addressed the foundations of archaeology in France, the religious backgrounds of the scientists involved, and their historical perspectives on magic and shamanism. Students appreciated the opportunity to be able to interact with this knowledgeable scholar on research that deconstructs boundaries between magic, religion, and science.

\section{Learning Outcomes and Evaluations}

In this section, we would like to add qualitative data to the literature on interdisciplinary teaching (Krometis et al., 2011; Lattuca, Voigt, \& Fath, 2004). We found that we were able to achieve the three learning goals of our seminar as evidenced by the outcomes we observed in the classroom. In particular, we would like to focus on how students were able to take the concept of paradigms and apply it to other classrooms, and the improvement in the quality of reading journals over time.

The readings on and concept of paradigms and personal epistemologies clearly made an impact on student learning. Throughout the progression of the semester, students would often let us know about how they have applied the concept of paradigmatic thinking to other classrooms. One student in particular remarked that it "made them feel smart" to bring up paradigms in a discussion in an English literature classroom, and that it was useful in deciphering the characters in the piece studied and their motivations. We found this learning outcome as evidence that students were able to take a quite difficult concept from the classroom and be able to apply it outside of the scope of topics taught in the seminar. We also found that students often returned to the concepts of paradigms later in the course, particularly when we discussed non-Western cultures and practices that may seem strange under the Western gaze. Oftentimes, we were able to foreground the construction of magic as a category by speaking in terms of paradigms-what is magic in one paradigm might be science in another.

Students were also able to synthesize and understand the readings assigned better throughout time, as evidenced by their reading journal grades. Using the reading journal grades to assess student learning is appropriate since we, the instructors who graded the journals, remained constant in our expectations for student writing throughout the semester. Figure 1 displays average student grades for the reading journals. We aggregated the grades for each reading journal into 10 points. There were 6 reading journals assigned throughout the semester. As is evidenced through the increase in the average from the first to fourth reading journal, students produced better writing as the semester progressed. The fifth reading journal average was slightly lower than that of the fourth, but still markedly better than the beginning of the semester. The sixth and final reading journal, however, was disappointing. One possible explanation for this outcome was the fact that the semester was coming to and end and the students were fatigued as major projects and papers proliferated for all their classes.

Journal of the Scholarship of Teaching and Learning, Vol. 17, No. 1, February 2017. josotl.indiana.edu 


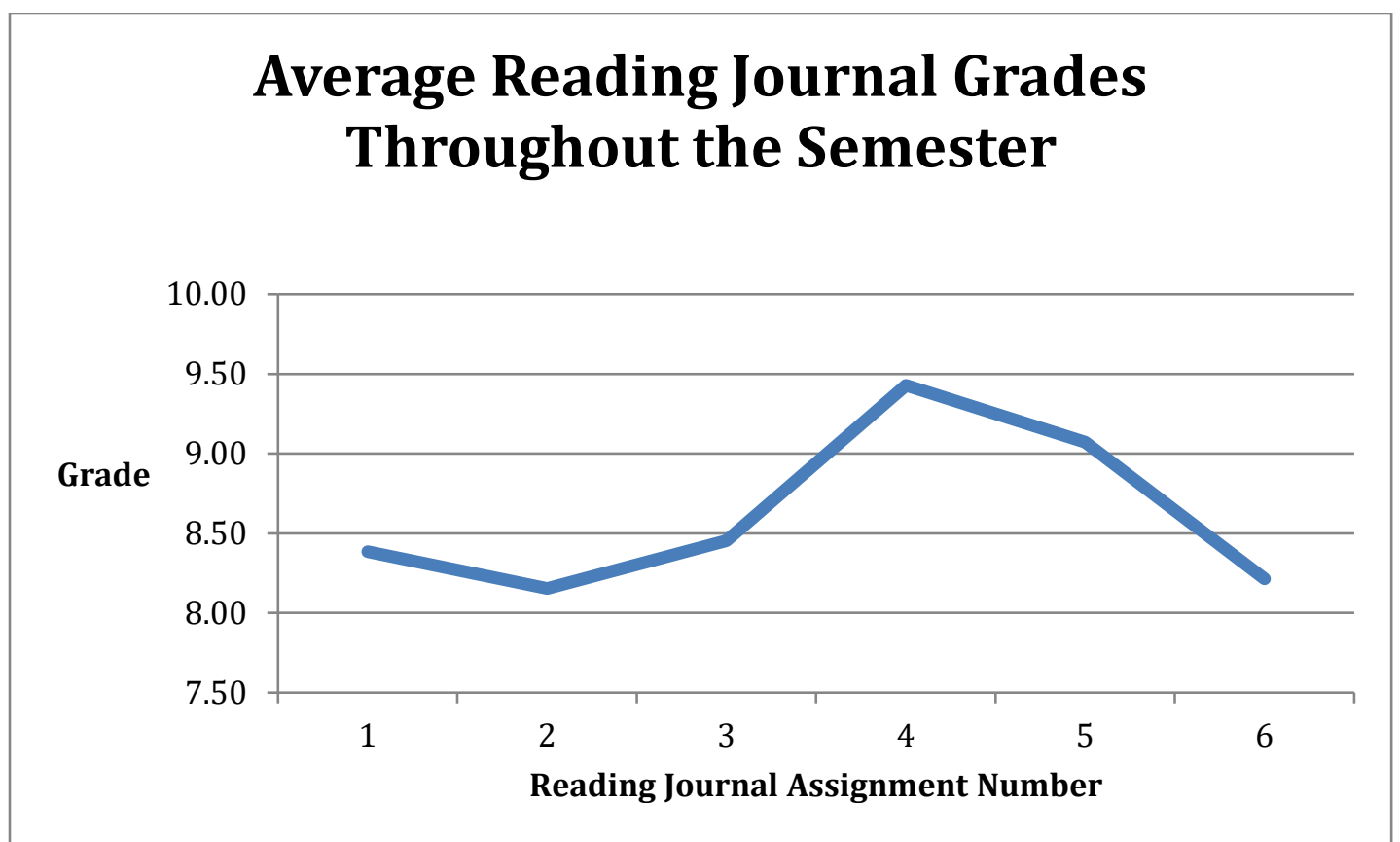

Figure 1. The progression of average reading journal grades throughout the semester.

We invited student evaluations twice throughout the semester, once during the middle of the semester and again at the end. On our mid-term evaluation, we made the following qualitative inquiries:

(1) If you were responsible for teaching this course, what parts of it would you keep without making any changes?

(2) Thus far, which lectures and/or class activities have you found most engaging and instructive?

(3) What would you change about the course if you were responsible for teaching it?

(4) Which lectures and/or class activities have been the least engaging and instructive?

By framing the questions in terms of potential changes, we hoped that students would think critically before answering.

In short, what we found was that students enjoyed collaborative projects most. For example, eight out of fourteen respondents thought that they would not change the student-led presentations. These were presentations wherein students, in groups of one or two, would prepare a short introductory presentation on assigned reading material. Oftentimes, these included background information on the author or the historical context within which a certain piece was written. The presentation leaders would then facilitate group discussion via questions that had been distributed the previous evening. As instructors, we found that students were eager to ensure classmates' presentations went well. As such, they were eager to answer questions and contribute to the class. Debates and class discussions were other components of the course that the students would have kept without amendment. In fact, half of the class identified debates as among the most engaging and instructive activities incorporated into the class.

Other things the students classified as clear positives included the use of videos and, begrudgingly, the reading journals. Criticisms had less to do with course content and structure, and Journal of the Scholarship of Teaching and Learning, Vol. 17, No. 1, February 2017. 
more to do with workload. Students found the initial amount of writing (one journal entry per day) to be excessive. They also found some of the reading assignments to be too long and dry. Some readings, like excerpts from Sociology of Religion (Weber, 1922) were deemed too difficult to understand. Students also disliked the readings for the initial methodology sections of the course, wherein the constituent methodologies of the three disciplines were introduced.

The mid-term evaluations were vital in discerning the strengths and possible weaknesses of the course. We were reassured by students' positive evaluations of the course content and goals, of the case studies we established and the interdisciplinary approaches we undertook to analyze them, and of the teaching team in general. Furthermore, by curbing the amount of reading and writing we assigned in future classes, we were able to redirect students' focus on the overall pedagogical objectives of the course, rather than the workload.

The final evaluations reflected that the students found that the course achieved its three main goals. A selection of write-in comments from the students included the following:

- “This First Year Seminar was interesting, but surprisingly difficult. I learned a lot.”

- "My favorite class this semester. Somehow, it managed to strengthen my confidence that I was on the right degree track while also convincing myself that I needed to pick up some random unrelated minors. Truly excellent.”

- "The description and background before going into the readings was beneficial in understanding.”

A selection of numerical ratings from the final course evaluation is displayed in Table 1. Students were asked to rate the statements on a scale from 0 to 5 , where 0 was 'strongly disagree' and 5 was 'strongly agree'. The department mean refers to the average of all other first-year seminars taught in the same semester. The evaluations showed that students found the seminar intellectually challenging and the breadth of topics covered to be refreshing. The only negative comments focused on the heavy course workload, teaching styles (students preferred lectures to discussions), and long writing assignments. It is also extremely important to note for the purposes of this paper that there was not a single complaint on the cohesiveness of the course as a whole, implying that despite the fact that the students found the early methodological introductions to each field boring, they were able to reconcile the different fields as time passed on and the course moved to analyzing case studies.

\section{Conclusion}

This paper illustrates a multifaceted way of teaching an interdisciplinary course. By building towards the interdisciplinary goal by taking a more varied and distinct route and introducing the separate main methodologies and fields represented by the instructors, we taught the students to utilize and recognize different viewpoints when analyzing historical and current events. Students developed a skill set that allowed them to criticize disciplinary boundaries and techniques and move towards new analyses of difficult contemporary and historical issues. As illustrated by the evaluations, students found the course cohesive despite the breadth of topics, a sign that the piecesto-picture method may be able to be successfully replicated in other classroom settings. Consistent with previous advice in the literature, in order to generalize this method to other interdisciplinary classrooms, it is crucial that all instructors involved must at least have a fundamental comprehension and basic command of the vocabulary of each of their fields when facing the

Journal of the Scholarship of Teaching and Learning, Vol. 17, No. 1, February 2017.

josotl.indiana.edu 
students (Davis, 2007). This is very important as the instructors presenting themselves as a 'unified front' may cement the cohesiveness of the course.

Table 1. A selection of final course evaluations.

\begin{tabular}{|c|c|c|}
\hline Seminar Characteristics & Mean & Department Mean \\
\hline $\begin{array}{l}\text { This seminar challenged me to } \\
\text { think deeply about the subject } \\
\text { matter. }\end{array}$ & 4.60 & 4.38 \\
\hline $\begin{array}{l}\text { This seminar promoted my } \\
\text { critical thinking about issues } \\
\text { raised in the course. }\end{array}$ & 4.65 & 4.42 \\
\hline $\begin{array}{l}\text { This seminar helped me } \\
\text { become aware of current issues } \\
\text { in this field. }\end{array}$ & 4.75 & 4.67 \\
\hline $\begin{array}{l}\text { This seminar taught me } \\
\text { academic skills that I will use } \\
\text { in other courses. }\end{array}$ & 4.39 & 4.12 \\
\hline $\begin{array}{l}\text { This seminar improved my } \\
\text { ability to express myself and } \\
\text { contribute effectively to } \\
\text { discussions. }\end{array}$ & 4.44 & 4.17 \\
\hline
\end{tabular}

The final note that we would like to make is regarding the teaching load for us, the graduate student instructors. Unlike the views expressed in the literature that stress on the intensive time requirements needed for team teaching a similarly-designed course (Krometis et al., 2011), we found that the workload was very manageable. We held joint office hours for three hours per week and were able to finish most of our grading work, which was evenly distributed amongst us and discussed together afterwards, during that time. It took the greatest proportion of our time to conceptualize the course, a process that took roughly two years with meetings on a monthly basis.

Overall, we found the entire experience of designing and teaching this unique course extremely rewarding, and emerged from the semester as not only better instructors, but also better academics. Although the initial task of designing the seminar was daunting, it proved fruitful as each of us also took this opportunity to learn more about other fields and methodologies.

\section{Acknowledgements}

We would like to thank the Royster Society of Fellows at The University of North Carolina at Chapel Hill for providing us with the opportunity to design and teach this course.

Journal of the Scholarship of Teaching and Learning, Vol. 17, No. 1, February 2017.

josotl.indiana.edu 


\section{References}

Barisonzi, J., \& Thorn, M. (2003). Teaching Revolution: Issues in Interdisciplinary Education. College Teaching, 51, 5-8.

Beck-Winchatz B., \& Parra, R.D. (2013). Finding Out What They Really Think: Assessing NonScience Majors' Views of the Nature of Science. College Teaching, 61, 131-137.

Borrego, M., \& Newsmander, L.K. (2008). Characteristics of Successful Cross-disciplinary Engineering Education Collaborations. Journal of Engineering Education, 97 (2), 123-133.

Casteel, M.A., \& Bridges, K.R. (2007). Goodbye Lecture: A Student-Led Seminar Approach for Teaching Upper Division Courses. Teaching of Psychology, 34(2), 107-110.

Caviglia, J.L., \& Hatley, H.J. (2004). Interdisciplinary teaching. International Journal of Sustainability in Higher Education, Vol 5(4), 395 - 403.

Davis, L.J. (2007). A Grand Unified Theory of Interdisciplinarity. The Chronicle of Higher Education, 53 (40), B9.

Eisen, A., \& Huang, J. (2014). Learning Science by Engaging Religion: A Novel Two-Course Approach for Biology Majors. College Teaching, 62, 25-31.

First Year Seminars Program. (n.d.) Retrieved February 23, 2017, from http://fys.unc.edu/.

Krometis, L.H., Clark, E.P., Gonzalez, V., \& Leslie, M.E. (2011). The “Death” of Disciplines: Development of a Team-Taught Course to Provide an Interdisciplinary Perspective for First-Year Students. College Teaching, 59, 73-78.

Lattuca, L.R., Voigt, L.J., \& Fath, K.Q. (2004). Does interdisciplinarity promote learning? Theoretical support and researchable questions. The Review of Higher Education, 28(1), 23-48.

Newell, W.H., \& Green, W.J. (1982). Defining and Teaching Interdisciplinary Studies. Improving College and University Teaching, 30, 23-30.

Shapiro E.J., \& Dempsey, C.J. (2010). Conflict Resolution in Team Teaching: A Case Study in Interdisciplinary Teaching. College Teaching, 56, 157-162.

Tomášková, S. (2013). Wayward Shamans: The Prehistory of an Idea. London: University of California Press.

Weber, M. (1922). The Sociology of Religion. Germany: J. C. B. Mohr.

Weinberg, A., \& Harding, C. (2004). Interdisciplinary Teaching and Collaboration in Higher Education: A Concept Whose Time Has Come. Washington University Journal of Law \& Policy, Vol. 14.

Journal of the Scholarship of Teaching and Learning, Vol. 17, No. 1, February 2017. josotl.indiana.edu 
Nungsari, Dedrick, and Patel

Journal of the Scholarship of Teaching and Learning, Vol. 17, No. 1, February 2017. josotl.indiana.edu 